\title{
Microalgae for Renewable Energy: Is it a Solution for Global Warming?
}

\author{
Meltem Conk Dalay \\ Bioengineering Department, Ege University, Izmir 35000, Turkey
}

\begin{abstract}
Microalgae could be a new sustainable energy source substituted for petroleum. They can produce high value biodiesel, bioethanol, bio-hydrogen, biogas, and that they are able to use waste water and nutrients, allowing for integration of such processes with waste treatment. Open ponds in hectares of area, could remove excess $\mathrm{CO}_{2}$ in atmosphere with photosynthesis. Large scale microalgal production in fields which are not suitable for agriculture could be a solution for $\mathrm{CO}_{2}$ capturing from the atmosphere. Sea water could be used for the culture medium not to consume the fresh water. However microalgae reduce the atmospheric $\mathrm{CO}_{2}$ while producing the organic material, using the biomass for either fuel production or food, feed, fertilizer, come out with $\mathrm{CO}_{2}$ release to the atmosphere, when burned by the engine, body and/or bacterial activities. So, microalgal growth can't reduce the $\mathrm{CO}_{2}$ however makes an important contribution to keep the atmospheric $\mathrm{CO}_{2}$ level stable. Long term solution for removing the $\mathrm{CO}_{2}$, could be possible with making durable biomaterials with microalgal biomass and capture the atmospheric $\mathrm{CO}_{2}$ by fixing into the materials and interrupt the carbon cycle for a long while.
\end{abstract}

Key words: Microalgae, biofuel production, biodiesel, bioethanol, biohydrogen, biogas.

\section{Introduction}

The authors have to understand past of the earth to make suggestions about the future. The earth we live on is living, dynamic and continuously changing. World appear to be overplaying this global warming issue as global warming is nothing new. It has happened in the past, not once but several times, giving rise to glacial-interglacial cycles.

Global warming is a phrase that refers to the effect on the climate of human activities, in particular the burning of fossil fuels (coal, oil and gas) and large-scale deforestation, which cause emissions to the atmosphere of large amounts of "greenhouse gases", of which the most important is carbon dioxide [1]. About half of the current emissions are being absorbed by the ocean and by land ecosystems, but this absorption is sensitive to climate, as well as to atmospheric carbon dioxide concentrations, creating a feedback loop [2]. Ecosystem models demonstrate the importance of examining the combined effects of the

Corresponding author: Meltem Dalay, Prof., main research field: microalgae. E-mail: meltemconkdalay@gmail.com. gradually rising concentration of atmospheric $\mathrm{CO}_{2}$ and the climatic change that attends it to be useful, and data-model fusion has become Models to forecast future changes need data support essential in global change research. There is a wealth of information on plant responses to $\mathrm{CO}_{2}$ and temperature, but there have been few ecosystem-scale experiments investigating the combined or interactive effects of $\mathrm{CO}_{2}$ enrichment and warming [3]. However, rapid warming in recent decades has been driven mainly by non- $\mathrm{CO}_{2}$ greenhouse gases (GHGs), such as chlorofluorocarbons, $\mathrm{CH}_{4}$, and $\mathrm{N}_{2} \mathrm{O}$, not by the products of fossil fuel burning [4]. The reduction of $\mathrm{CH}_{4}$ and $\mathrm{O}_{3}$ precursors in the last 20 years, leads to a decline in the rate of global warming. From 1978 to 1996, the U.S. Department of Energy's Office of Fuels Development funded a program to develop renewable transportation fuels from algae. The main focus of the program, known as the Aquatic Species Program (or ASP) was the production of biodiesel from high lipid-content algae grown in ponds, utilizing waste $\mathrm{CO}_{2}$ from coal fired power plants [5]. 
While scientists have been analysing global warming for more than half a century, nations took the first formal step to solve the global warming only about fifteen years ago, under the United Nations Framework Convention on Climate Change (FCCC) [6]. The first binding international agreement on climate change, the Kyoto Protocol, entered into force on 16 February 2005.

\section{Materials}

\subsection{Microalgae as Energy Source}

\subsubsection{Biodiesel}

Several types of renewable biofuels can be produced from microalgae:

- Biodiesel production by transestrification of algal oils (Table 1);

- Methane production by anaerobic digestion of algal biomass;

- Photobiologically produced biohydrogen [7];

- Bioethanol production from cellulosic wastes of microalgae.

Also biofuels can be produced by thermal liquefaction or pyrolysis of microalgae.

Certain microalgae can accumulate $70 \%$ and more of dry weight of microalgal biomass as hydrocarbons. Therefore microalgae are potential sources of biofuels [8].
Algae are photosynthetic organisms that found in marine and freshwater environments. They utilize sunlight to convert chemical energy. This chemical energy is used to drive chemical reactions such as the formation of sugars or the fixation of nitrogen into amino acids, the building blocks for protein synthesis. Microalgae are sunlight-driven cell factories that convert carbon dioxide to potential biofuels, foods and fine bioactive chemicals [9].

Microalgae contains lipids and fatty acids in their cells as membrane component, storage products, metabolites and resources of energy. Especially diatoms, and cyanophyta are the most dominant lipid containing microalgae. Some microalgae could contain $77 \%$ lipid in its dry weight.

There are some advantages to obtain lipids from microalgae when compared with agricultural products:

They have shown shorter doubling time and higher growth rate when compared with other vegetative products like canola, corn or soybean.

Microalgae can be grown in areas which are not available for agriculture.

As microalgae are exponentially growing in optimal conditions, they can be harvested frequently and the oil production per squre meter is much more when compared with oil plants.

Microalgae production needs less water and either

Table 1 Oil content of some microalgae [9].

\begin{tabular}{ll}
\hline Microalga & Oil content (\% dry wt) \\
\hline Botryococcus braunii & $25-75$ \\
Chlorella sp. & $28-32$ \\
Crypthecodinium cohnii & 20 \\
Cylindrotheca sp. & $16-37$ \\
Dunaliella primolecta & 23 \\
Isochrysis sp. & $25-33$ \\
Monallanthus salina & $>20$ \\
Nannochloris sp. & $20-35$ \\
Nannochloropsis sp. & $31-68$ \\
Neochloris oleoabundans & $35-54$ \\
Nitzschia sp. & $45-47$ \\
Phaeodactylum tricornutum & $20-30$ \\
Schizochytrium sp. & $50-77$ \\
Tetraselmis sueica & $15-23$ \\
\hline
\end{tabular}


brackish or sea water could be used for microalgal production.

They can be produced easily in everywhere, has enough sunshine.

Their cultivation is much more cost efficient when compared with agricultural products.

Wastes could be used as culture medium to reduce the production expenses while making bioremediation.

They use $\mathrm{CO}_{2}$ for photosynthesis and reduce increasing atmospheric $\mathrm{CO}_{2}$ causing the global warming.

For replacing the petroleum diesel with biodiesel, agricultural lands should be used. This brings another problem. Starvation becomes an important case around the world. So it isn't a realistic solution to use productive and cultivated land for food instead of fuel production while there's no need to use productive lands for microalgal production. Additionally it's shown in Table 2 that microalgae requires less land area to produce oil.

The lipid and fatty acid contents of microalgae can vary with culture conditions. In some cases, lipid content can be enhanced by nitrogen starvation or other stress factors. Nitrogen deficiency in microalgae and silicon deficiency in diatoms triggers the lipid accumulation. Also Si depletion increases the oil levels in diatoms.

However, the stress conditions cause the rise in lipid content, the biomass doesn't grow in this unfavourable conditions. That's why, this type of production should be done by two steps. First phase: production in optimum conditions for maximum growth rate and second phase: production in stress conditions for rising the oil content. Photobioreactors are the most suitable devices for that production as the conditions should be required to be controlled in that type of production.

As mentioned above, biodiesel production from microalgae has been thought as a solution for global warming caused by greenhouse gases, basically $\mathrm{CO}_{2}$. Both plants and animals respire, so they release $\mathrm{CO}_{2}$ during respiration however plants just happen to consume more $\mathrm{CO}_{2}$ through photosynthesis than they can produce. Photosynthesis process is the production of organic compounds, as primary production, by using atmospheric or aquatic carbon dioxide via sun energy. Net primary production is the difference between gross primary production which is the total $\mathrm{CO}_{2}$ that fixed by the plant in photosynthesis and the amount used for plant respiration. Approximately half of the dry weight of the microalgal biomass is carbon which is typically derived from carbon dioxide [10]. Therefore, producing 100 tons of algal biomass fixes roughly 183 tons of carbon dioxide [11]. At the result of their photosynthetic activities, plants and microalgae supply $\mathrm{O}_{2}$ to the atmosphere while using the $\mathrm{CO}_{2}$. On the other hand, that carbon returns to the

Table 2 Comparison of some sources of biodiesel [9].

\begin{tabular}{llll}
\hline & $\begin{array}{l}\text { Oil yield } \\
(\mathrm{L} / \mathrm{ha})\end{array}$ & $\begin{array}{l}\text { Land area needed } \\
(\mathrm{M} \mathrm{ha})^{\mathrm{a}}\end{array}$ & Percent of existing US cropping area $^{\mathrm{a}}$ \\
\hline Corn & 172 & 1,540 & 846 \\
Soybean & 446 & 594 & 326 \\
Canola & 1,190 & 223 & 122 \\
Jatropha & 1,892 & 140 & 77 \\
Coconut & 2,689 & 99 & 54 \\
Oil palm & 5,950 & 45 & 24 \\
Microalgae $^{\mathrm{b}}$ & 136,900 & 2 & 1.1 \\
Microalgae $^{\mathrm{c}}$ & 58,700 & 4.5 & 2.5 \\
\hline
\end{tabular}

${ }^{*}$ For meeting $50 \%$ of all transport fuel needs of the United States.

${ }^{\mathrm{b}} 70 \%$ oil (by wt) in biomass.

c $30 \%$ oil (by wt) in biomass. 
physical environment in a number of ways. One of them is death of plants and animals. The other is burning of organic material. By far, most of the carbon returns to the physical environment through the respiration of $\mathrm{CO}_{2}$.

As a result, making biodiesel from microalgae doesn't completely reduce the $\mathrm{CO}_{2}$ in the atmosphere but it is a very important aid to remain the $\mathrm{CO}_{2}$ level. So that, microalgal biodiesel could be a solution to stop rising $\mathrm{CO}_{2}$ in the atmosphere.

\subsubsection{Bioethanol}

Energy biotechnology uses carbon stored during photosynthesis from cyanobacteria, algae or plants This carbon can then be converted to energy carriers, such as biodiesel or ethanol [10]. Bioethanol can be produced from cellulosic feedstocks. One major problem with bioethanol production is the availability of raw materials for the production [11]. Ethanol made from starch and sugars in traditional agricultural crops, ethanol made from biomass called as "bioethanol" [12]. Ethanol-producing microorganisms are, mainly Zymomonas mobilis and Saccharomyces cerevisiae However, there are several Gram-negative bacteria such as Escherichia coli, Klebsiella oxytoca, Z. mobilis, Gram-positive bacteria such as Clostridium cellulolyticum, Lactobacillus casei and several yeast strains for bioethanol production from cellulosic substrates.

They produce ethanol from a wide spectrum of sugars and lignocellulosic substrates. Cellulosic biomass from agricultural and forestry residues, waste paper and industrial wastes could be used as an ideal and inexpensive source of sugar for sustainable fermentation into transportation fuel [13]. Hydrolysis of starch and cellulose followed by fermentation of glucose to ethanol Fig. 1 shows the flow diagram of this pathway.

Microalgae contains high starch. So the biomass could be used as substrate for bioethanol fermentation after the lipids separated for biodiesel production. These two phase process could give a chance to use

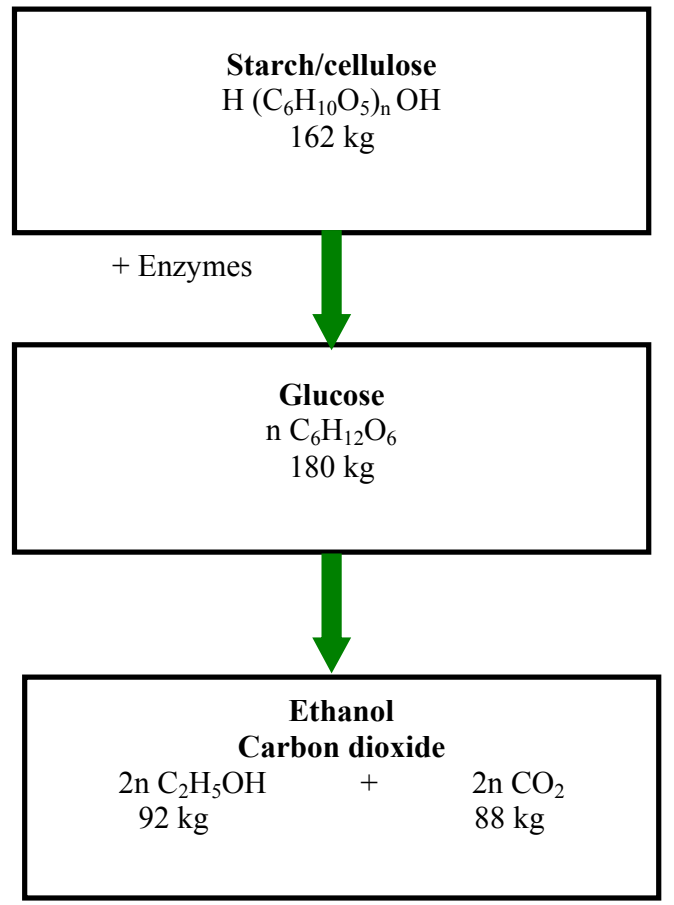

Fig. 1 Bioethanol production pathway [14].

the same biomass for either biodiesel or bioethanol production. The advantages of microalgal starch, as substrate material, for bioethanol production are same with biodiesel when compared with agricultural starch sources.

\subsubsection{Bio-hydrogen}

The production of $\mathrm{H}_{2}$ gas from water and sunlight using microalgae, "biophotolysis", has been a subject of applied research since the early 1970's [15]. In 1999, NREL completed a preliminary cost analysis of photobiological hydrogen production from Chlamydomonas reinhardtii [16]. The increase in the cost of energy, on the one hand, and the problem of global warming, on the other, has fostered considerable international efforts to discover a sustainable way by which to produce energy with zero $\mathrm{CO}_{2}$ emission [17]. In 1942, Gaffron and Rubin discovered the $\mathrm{H}_{2}$ production process with Scenedesmus [18]. In 2000, the process was propagated by Melis et al. and the $\mathrm{H}_{2}$ production period was prolonged by inorganic sulphur depreciation [18]. However, wild types of microalgae produce hydrogen, mutant types produce significantly more yield. Torzillo et al. [16] produced mutant and 
Table $3 \mathrm{H}_{2}$ productions recorded with the mutant, the wild type and the CC124 [16].

\begin{tabular}{|c|c|c|c|c|c|c|c|c|}
\hline \multirow[t]{2}{*}{ Strain } & \multirow[t]{2}{*}{$\begin{array}{l}\Delta \mathrm{F} / \Delta \mathrm{F}_{\mathrm{m}}^{\prime} \\
\text { (at the started of } \\
\text { the experiment) }\end{array}$} & \multicolumn{2}{|c|}{$\Delta \mathrm{F} / \Delta \mathrm{F}_{\mathrm{m}}^{\prime}$ Lag phase ${ }^{\mathrm{a}}$} & \multirow{2}{*}{$\begin{array}{l}\text { Lenght of the } \mathrm{H}_{2} \\
\text { production phase }\end{array}$} & \multirow{2}{*}{$\begin{array}{l}\mathrm{H}_{2} \text { output } \\
\mathrm{ml} \cdot \mathrm{l}^{-1} \pm \text { S.D. }\end{array}$} & \multicolumn{2}{|c|}{ Mean $\mathrm{H}_{2}$ production rates } & \multirow{2}{*}{$\begin{array}{l}\begin{array}{l}\mathrm{H}_{2} \max . \\
\text { prod. rate }\end{array} \\
\mathrm{ml} \cdot \mathrm{l}^{-1} \cdot \mathrm{h}^{-1}\end{array}$} \\
\hline & & & Hours \pm S.D. & & & $\begin{array}{l}\mathrm{ml} \cdot 1^{-1} \cdot \mathrm{h}^{-1} \pm \\
\text { S.D. }\end{array}$ & $\begin{array}{l}\mathrm{ml} \mathrm{H}_{2} \mathrm{~g} \mathrm{Chl}^{-1} \\
\mathrm{~h}^{-1} \pm \text { S.D. }\end{array}$ & \\
\hline WT & 0.700 & 0.110 & $50 \pm 20$ & $98 \pm 4$ & $29 \pm 9$ & $0.30 \pm 0.11$ & $27 \pm 9$ & 0.60 \\
\hline L1591-N230Y & 0.533 & 0.148 & $37 \pm 6$ & $285 \pm 53$ & $504 \pm 22$ & $1.81 \pm 0.35$ & $166 \pm 29$ & 5.77 \\
\hline CC-124 & 0.708 & 0.207 & $16 \pm 4$ & $53 \pm 4$ & $80 \pm 8$ & $1.51 \pm 0.04$ & $139 \pm 3$ & 2.09 \\
\hline
\end{tabular}

*S. D.: standard deviation.

The performance of the strains was tested under the same standard conditions (i.e. $12 \mathrm{mg} \cdot \mathrm{l}^{-1} \mathrm{Chl}$ and $70 \mu \mathrm{mol}$ photons $\mathrm{m}^{-2} \cdot \mathrm{s}^{-1}$ on both the sides of the photobioreactor). Changes in effective quantum yield of PSII $\left(\Delta \mathrm{F} / \Delta \mathrm{F}^{\prime} \mathrm{m}\right)$ are also shown.

a Time before $\mathrm{H}_{2}$ production started.

${ }^{\mathrm{b}}$ Maximum $\mathrm{H}_{2}$ production rate measured over a period of at least $10 \mathrm{~h}$ during which the rate remained constant, expect for WT which was averaged over a period of $3 \mathrm{~h}$.

wild type of the strain CC124 together is shown in Table 3 and determined that, $\mathrm{H}_{2}$ production achieved with the mutant (about $500 \mathrm{ml} \cdot \mathrm{l}^{-1}$ ), was higher than that obtained with the WT $\left(29 \mathrm{ml} \cdot \mathrm{l}^{-1}\right)$. Moreover, the mutant also performed about 5-times better than the CC124.

The ideal algal hydrogen production system would meet the following criteria listed by Amos [16].

(1) It would have no cell wasting - the cells would naturally maintain the same cell density without a net increase in cell mass and new cells would obtain nutrients through cryptic growth off dead cells;

(2) The pond depth would be just enough to maximize light adsorption, but no deeper;

(3) The cells would have a reduced antennae size so that they would adsorb only as many photons as they could convert to hydrogen and no more. This would allow the additional photons to pass deeper into the algal solution and be adsorbed by cells further down in the liquid. All the incident photons would thereby be absorbed and converted to hydrogen;

(4) All electrons passing through PS-II would be used for hydrogen production with no side reactions;

(5) The cells would produce hydrogen at the maximum rate at which they could process electrons without any concerns with oxygen production and inhibition;

(6) The cells would be contained in a cheap, durable translucent reactor material that fully transmitted all required wavelengths, would have a low hydrogen permeation rate to contain the hydrogen, and would not allow algae cells to fasten to the inner surface and block the sunlight.

Although there are many studies and comments about hydrogen production and its liability, hydrogen production from microalgae doesn't seem feasible, in existing circumstances, as large scale hydrogen production is more expensive and complicated than determined with lab scale experiments. The most important cost of this process is the photobioreactor while the second major cost factor is the storage. It isn't simple to store the produced hydrogen in a tank [19]. On the other hand, it is known that the $\mathrm{H}_{2}$ production rate by the mutant algal strains is higher. This requires the system to be supported by fesh mutant cultures continuously not to let the culture lose the mutant characteristics. However there are some difficulties in large scale production of mutant strains, contribution of genetic engineering, in the future, could be important for improving $\mathrm{H}_{2}$ production.

\subsubsection{Biogas}

Biogas is a renewable energy source. It can be used for heating or electricity production and it can also be replaced to natural gas when compressed. Biogas can be produced by fermentation or digestion of the biomass. Agricultural residues, manure, sewage sludge or industrial wastes, like food, beverage, pulp and paper, could be used as biomass for fermentation. 
In that fermentation process, anaerobic bacteria produces large quantities of methane (55-65\%), about $30 \%$ Carbon Dioxide, along with small amounts of hydrogen sulphide, water vapour and other products [20]. Biogas production is a 4 steps process which each steps accompanied by different bacteria groups.

First step is Hydrolysis: organic material is broken down to smaller molecules during this stage. Monosaccharaides, amino acids and fatty acids are the outputs of this process.

Second step is acidogenesis: Acid forming bacteria play role in this process and acidity increases. Organic acids and alcohols are the outputs. Third step is acetogenesis: acid forming bacteria produce acetic acid, carbon dioxide and hydrogen which are precursors of methane formation. Last step is methanogenesis: which the production of methane, carbon dioxide and water by methane bacteria is accomplished [21].

Today, crop plants like maize are preferred as substrates for renewable biogas production. In 2010, Mussgnug et al. searched the suitability of six dominant microalgae species (freshwater and saltwater algae and cyanobacteria) as alternative substrates for biogas production [22]. They investigated that, the methane content of biogas from microalgae was $7-13 \%$ higher compared to biogas from maize silage and concluded that, selected algae species can be good substrates for biogas production and that anaerobic fermentation can seriously be considered as final step in future microalgae-based bio refinery concepts.

It is more feasible to use microalgae for waste water treatment and produce the biomass and then using the biomass for biogas production for renewable energy production.

\section{Results and Discussion}

Nations are now beginning to consider the structure of climate-change policies for the period after 2008-2012. Some countries, states, cities, companies, and even universities are adopting their own climate-change policies [7].

Carbon cycle in the atmosphere was naturally in a balance before human activities became a significant disturbance. Fig. 2 shows the carbon cycle.

For several thousand years before the beginning of

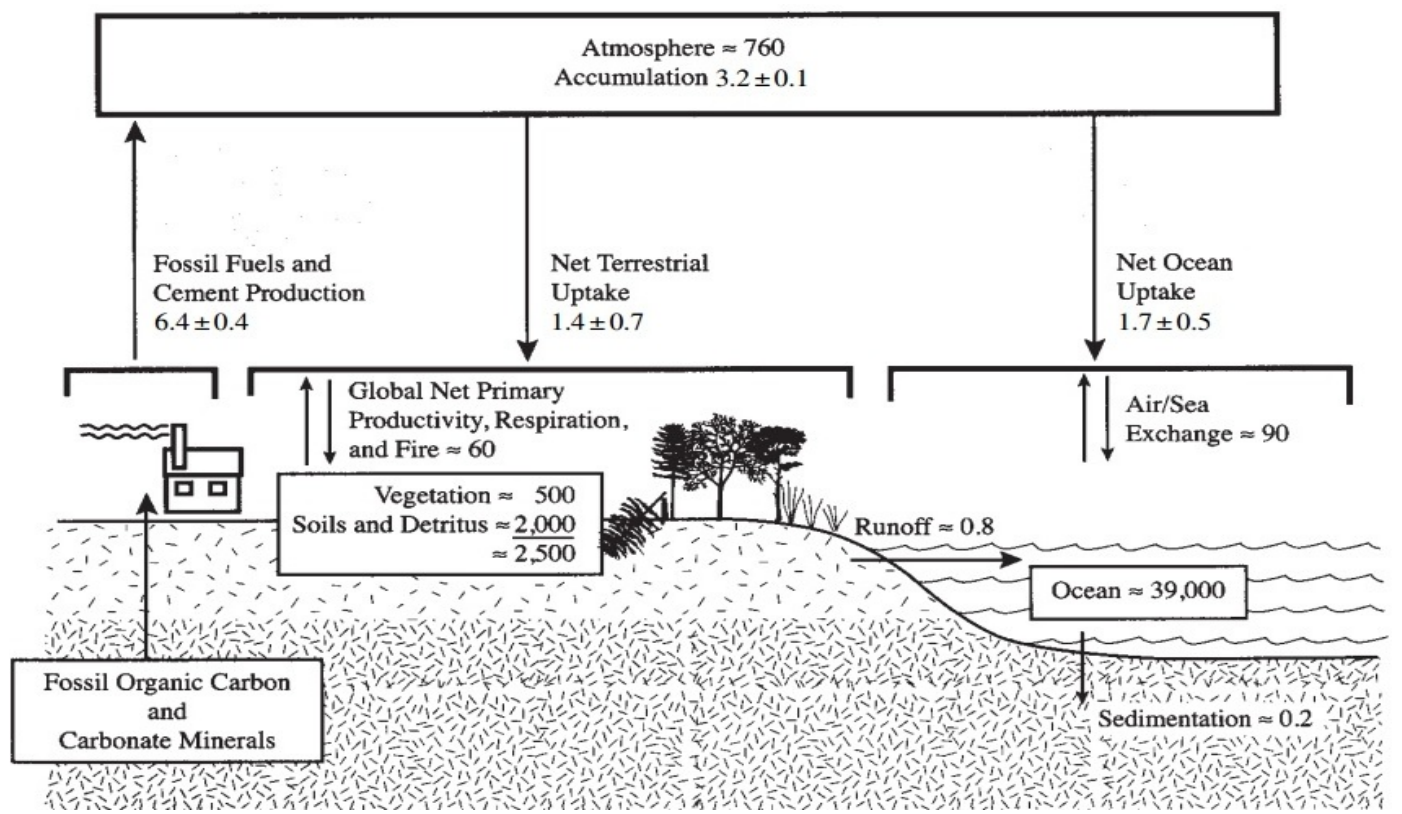

Fig. 2 The global carbon cycle, showing the carbon stocks in reservoirs (in GtC) and carbon flows (in Gt/year) relevant to the anthropogenic perturbation as annual averages over the decade from 1989 to 1998 . The units are thousand millions of tonnes or gigatonnes (Gt) [1]. 
industrialization around 1750, a steady balance was maintained, such that the mixing ratio (or mole fraction) of $\mathrm{CO}_{2}$ in the atmosphere as measured from ice cores kept within about 10 ppm (parts per million) of a mean value of about $280 \mathrm{ppm}$ [1]. The increase in atmospheric $\mathrm{CO}_{2}$ in recent decades represents about half of the emissions from fossil fuels and changes in tropical land use; the remaining $\mathrm{CO}_{2}$ from these sources is taken up by the ocean, terrestrial biosphere, and soils [4]. The flat growth rate of $\mathrm{CO}_{2}$ forcing, despite increased emissions, is at least in part a reflection of increased terrestrial sequestration of carbon in the 1990s [23].

The advantages of microalgae in greenhouse gas mitigation are that they can utilize $\mathrm{CO}_{2}$ from power plant and other flue gases directly, that they can produce high value liquid and gaseous fuels (biodiesel, hydrocarbons, ethanol, methane, hydrogen), that they could potentially exhibit very high biomass productivities approaching the theoretical limits of photosynthesis (about 10\% solar conversion efficiency), and that they are able to use waste water and nutrients, allowing for integration of such processes with waste treatment [24].

Another important advantage of microalgae is that, unlike other oil crops, they grow extremely rapidly and commonly double their biomass within $24 \mathrm{~h}$. In fact, the biomass doubling time for microalgae during exponential growth can be as short as $3.5 \mathrm{~h}$ [11]. This is significantly quicker than the doubling time of all plants and forests. Doubling the plant biomass in one day is impossible in any conditions. That means that large scale microalgal production in fields which are not suitable for agriculture could be a solution for $\mathrm{CO}_{2}$ capturing from the atmosphere. Sea water could be used for the culture medium not to consume the fresh water. However microalgae reduce the atmospheric $\mathrm{CO}_{2}$ while producing the organic material, using the biomass for either fuel production or food, feed, fertilizer, come out with $\mathrm{CO}_{2}$ release to the atmosphere, when burned by the engine, body and/or bacterial activities. So, microalgal growth can't reduce the $\mathrm{CO}_{2}$ however makes an important contribution to keep the atmospheric $\mathrm{CO}_{2}$ level stable. Long term solution for removing the $\mathrm{CO}_{2}$, could be possible with making durable biomaterials with microalgal biomass and capture the atmospheric $\mathrm{CO}_{2}$ by fixing into the materials and interrupt the carbon cycle for a long while.

\section{Conclusion}

Recent research has shown that algae are quite successful when grown using wastewater and recycled nutrients from agricultural sources. Despite the hurdles to the economically viable production of biofuels from algae, these organisms still represent one of the best options available as a source of bioenergy. Their success will largely depend on the interdisciplinary research and collaboration between engineers, chemists, and biologists that will be required to optimize the growth, harvest, and processing of these organisms to create an extremely versatile and efficient production platform for bioenergy.

\section{References}

[1] Houghton, J. 2005. "Global Warming." Reports on Progress Physics 68: 1343-1403.

[2] Cox, P. M. 2000. "Acceleration of Global Warming Due to Carbon-cycle Feedbacks in a Coupled Climate Model." Nature 408: 184-187.

[3] Vitousek, P., Beyond, M. 1994. "Global Warmıng: Ecology and Global Change." Ecology 75 (7): 1861-1876.

[4] Hansen, J., Sato, M., Ruedy, R., Lacis, A., Oinas, V. 2000. "Global Warming in the Twenty-first Century: An Alternative Scenario." In Proceedings of the National Academy of Sciences 97: 9875-9880.

[5] Sheehan, J., Dunahay, T., Benemann, J., and Roessler, P. 1998. A Look Back at the U.S. Department of Energy's Aquatic Species Program. U.S.: Biodiesel from Algae.

[6] Nordhaus, W. D. 2011. "To Tax or Not to Tax: Alternative Approaches to Slowing Global Warming." Review of Environmental Economics and Policy 1: 26-44.

[7] Chisti Y. 2005. "Microalgae as Sustainable Cell Factories.” J. Environ. Engin. Management 5: 261-274. 
[8] Chisti, Y. 2007. "Biodiesel from Microalgae." Biotechnology Advances 25: 294-306.

[9] Chisti, Y. 2007. "Biodiesel from Microalgae." Biotechnology Advances 25: 294-306.

[10] Chisti, Y. 2008. "Biodiesel from Microalgae Beats Bioethanol." Trends in Biotechnology 26: 126-131.

[11] Balat, M., Balat H., and Öz, C. 2008. "Progress in Bioethanol Processing." In Progress in Energy and Combustion Science 34: 551-573.

[12] Sheehan, J., and Himmel, M. 1999. "Enzymes, Energy, and the Environment: A Strategic Perspective on the U.S. Department of Energy's Research and Development Activities for Bioethanol." Biotechnology Progress 15: 817-827.

[13] Senthilkumar, V., and Gunasekaran, P. 2005. "Bioethanol Production from Cellulosic Substrates: Engineered Bacteria and Process Integration Challenges." Journal of Scientific \& Industrial Resaerch 64: 845-853.

[14] European Biomass Industry Association (EUBIA) Reports. "RESTMAC-Bioethanol Production and Use" European Biomass Industry Association. Accessed: January $16, \quad 2013$. http://www.eubia.org/index.php/news-events/news/190-e ubia-report.

[15] Benemann J. R. 2000. "Hydrogen Production by Microalgae." Journal of Applied Phycology 12: 291-300.

[16] Amos, W. A. 2004. Updated Cost Analysis of Photobiological Hydrogen Production from Chlamydomonas Reinhardtii Green Algae. Nation: National Renewable Energy Laboratories.

[17] Torzillo, G., Scomaa, A., Faralonia, C., Enaa, A., and Johanningmeierb, U. 2009. "Increased Hydrogen
Photoproduction by Means of a Sulfur-deprived Chlamydomonas Reinhardtii D1 Protein Mutant." Int. Journal of Hydrogen Energy 34: 4529-4536.

[18] Gaffron H., and Rubin J. 1942. "Fermentative and Photochemical Production of Hydrogen in Algae." J. Gen. Physiol. 26: 219-240.

[19] Melis A., Zhang L., Forestier M., Ghirardi M. L., and Seibert M. 2000. "Sustained Photobiological Hydrogen Gas Production upon Reversible Inactivation of Oxygen Evolution in the Green Alga Chlamydomonas Reinhardtii.” Plant Physiol 22: 127-136.

[20] Fox, R. 1983. "Algoculture. The Microalgae Spirulina (Cyanophyceae). A Study of the Conditions Necessary for Their Growth. Development of Original Production Systems, Particularly with Referance to a Village Ecocystem.” Ph.D. thessis, Univ. Louis Pasteur.

[21] Speece, R. E. 1983. "Anaerobic Biotechnology for Industrial Wastewater Treatment." Environmental Science \& Technology 17 (9): 416A-427A.

[22] Mussgnug, J. H., Klassen, V., Schlüter, A., Kruse, O. 2010. "Microalgae as Substrates for Fermentative Biogas Production in a Combined Biorefinery Concept." $J$. Biotechnol 150 (1): 51-6.

[23] Battle, M. M. L., Bender, P. P., Tans, J. W. C., White, J. T., Ellis, T., Conway, R. J., and Francey. 2000. "Global Carbon Sinks and Their Variability Inferred from Atmospheric $\mathrm{O}_{2}$ and D13C." Science 287: 2467-2470.

[24] Huesemann, M. H. 2006. "Can Advances in Science and Technology Prevent Globalwarmıng? A Critical Review of Limitations and Challenges." Mitigation and Adaptation Strategies for Global Change 11: 539-577. 